\section{Albumin depletion method for improved plasma glycoprotein analysis by two- dimensional difference gel electrophoresis}

\author{
Henry Brzeski ${ }^{1}$, Richard A. Katenhusen ${ }^{1}$, Anthony G. Sullivan ${ }^{1}$, Stephen \\ Russell $^{1}$, Alisha George ${ }^{1}$, Richard I. Somiari ${ }^{1}$, and Craig Shriver ${ }^{2}$ \\ ${ }^{1}$ Windber Research Institute, Windber, PA and ${ }^{2}$ Walter Reed Army Medical Center, \\ Washington, DC, USA
}

BioTechniques 35:1128-1132 (December 2003)

Serum and plasma are important media for monitoring biological markers of disease $(1,2)$. Proteomic methods have been employed for the identification of putative protein markers in serum that could potentially be useful in diagnosis, prognosis, treatment, and early detection of a number of diseases (3-8). The success of emerging clinical proteomics and large-scale biology techniques will, however, depend on the development and availabiity of systems for rapid purification, prefractionation, and analysis of proteins (9). Analysis of proteins from complex mixtures is routinely perfomed by 2-dimensional polyacrylamide gel electrophoresis (2-D PAGE). Although no other method currently provides as much proteome information as 2-D PAGE, it is still limited in its application because of problems such as spot fusion and limited visualization of low abundant proteins (10). Proteomic analysis of human serum and plasma by 2-dimensional electrophoresis is particularly challenging, mainly because of the natural high levels of human serum albumin (HSA), which constitutes $60 \%-80 \%$ of the total protein. Prefractionation and HSA depletion permits higher protein loading, thus allowing for more low abundant proteins to be observed and their relative expression levels quantified (10). Many methods have been described for prefractionation and/or HSA depletion $(1,9,10)$, but many of the commercially available methods were difficult to use reproducibly in our hands, and the monoclonal antibody-based methods were expensive. We are interested in high-throughput serum/plasma glycoprotein analysis using 2-dimensional difference gel electrophoresis (2-D DIGE) and wished to develop a protocol that would improve the selective display of these proteins. In this work, we describe a novel HSA depletion method involving lectin-agarose affinity chromotography that is suitable for depletion of albumin prior to proteomic analysis of plasma by 2-D DIGE.

Two plasma samples were obtained from a fully informed and consenting adult donor at two different time points. Fifty microliters of each plasma sample were diluted with an equal volume of $0.1 \mathrm{M}$ sodium phosphate, $\mathrm{pH}$ 7.0, 0.4 M $\mathrm{NaCl}, 0.1 \%$ (w/v) sodium dodecyl sulfate (SDS) (11), and mixed with wheat germ agglutinin (WGA) coupled to agarose beads (lectin-agarose Triticum vulgaris; Sigma, St. Louis, MO, USA). The beads were washed 3 times with $0.05 \mathrm{M}$ sodium phosphate, $\mathrm{pH} 7.0,0.2 \mathrm{M} \mathrm{NaCl}, 0.05 \%$ (w/v) SDS (11) to remove nonbound proteins, and the bound proteins were eluted using either $0.3 \mathrm{M} \mathrm{N}$-acetyl glucosamine (sample 1) or $0.3 \mathrm{M} \mathrm{N}$-acetyl neuraminic acid (sample 2) in $0.05 \mathrm{M}$ sodium phosphate, $\mathrm{pH} 7.0,0.2 \mathrm{M} \mathrm{NaCl}, 0.05 \%$ (w/v) SDS (11). The eluted proteins were precipitated to remove contaminating ionic material (Perfect-FOCUS ${ }^{\mathrm{TM}}$; Genotech, St. Louis, MO, USA) and were labeled with $\mathrm{Cy}^{\mathrm{TM}} 3$ (sample 1) or Cy5 (sample 2; Amersham Biosciences, Piscataway, NJ, USA). Isoelectric focusing (IEF) focusing was performed using a precast IEF strip (pH 3.0-7.0), and second dimension separation was carried out on $12 \%$ polyacrylamide gels. The gels were scanned for Cy3/Cy5 using a Typhoon ${ }^{\mathrm{TM}}$ 9400 Imager (Amersham Biosciences), and the files were then subjected to quantitative analysis using DeCyder ${ }^{\mathrm{TM}}$ software (Amersham Biosciences). Spots of interest were excised, processed robotically using an Ettan ${ }^{\mathrm{TM}}$ Spot Handling workstation (Amersham Biosciences), and identified by matrix-assisted laser desorption ionization time-of-flight (MALDI-TOF) (Ettan Pro; Amersham Biosciences) or liquid chromatography/ mass spectrometry/mass spectrometry (LC/MS/MS) (Q-Tof ${ }^{\mathrm{TM}}$ API-US; Waters, Milford, MA, USA).

This method was developed based
Table 1. Proteins Identified from Gel Spots Picked in the 50-70 kDa Range

\begin{tabular}{|c|c|}
\hline Carboxypeptidase N 83-kDa chain (carboxypeptidase $\mathrm{N}$ regulatory subunit) & P22792 \\
\hline Angiotensinogen & P01019 \\
\hline Complement factor B precursor (EC 3.4.21.47) (C3/C5 convertase) & P00751 \\
\hline Inter- $\alpha$-trypsin inhibitor heavy chain $\mathrm{H} 4$ & Q14624 \\
\hline Keratin, type I cytoskeletal 10 (cytokeratin 10) & $\mathrm{P} 13645$ \\
\hline Hemopexin ( $\beta$-1B-glycoprotein) & P02790 \\
\hline$\alpha-1$-Antichymotrypsin & P01011 \\
\hline Serotransferrin (transferrin) & P02787 \\
\hline Insulin-like growth factor binding protein complex acid labile chain (ALS) & P35858 \\
\hline Coagulation factor XIII B chain & P05160 \\
\hline Antithrombin-III & P01008 \\
\hline$\alpha-1$-Antitrypsin & P01009 \\
\hline$\beta$-2-Glycoprotein I & P02749 \\
\hline$\alpha-2-H S$-glycoprotein (fetuin-A) ( $\alpha-2-Z$-globulin) & P02765 \\
\hline$\alpha-1$-Acid glycoprotein 2 & P19652 \\
\hline Haptoglobin-1 & P00737 \\
\hline Clusterin & P10909 \\
\hline \multicolumn{2}{|c|}{$\begin{array}{l}\text { Here, } 17 \text { proteins in the } 55-70 \mathrm{kDa} \text { range were identified using the program Profound on the basi } \\
\text { of their peptide mass fingerprints determined by matrix-assisted laser desorption ionization (MALD } \\
\text { analysis. }\end{array}$} \\
\hline
\end{tabular}


on the assumption that the majority of serum and plasma proteins, with the exception of serum albumin, would be glycosylated. This method used the ability of lectins to bind specific sugars as a way of purifying glycoproteins. It also used the fact that lectins have multiple sugar binding specificities to carry out some differential glycosylation analysis when comparing elution patterns with different sugars. Figure 1, a and $b$, shows representative 2-D DIGE images, which provide an indication of the protein abundance changes between sample 1 and sample 2. Sample 1 (Cy3-labeled proteins) is colored red, and sample 2 (Cy5-labeled proteins) is colored blue. Proteins expressed at similar levels in each of the two samples appear purple. Two images are presented that show the proteins eluted by either $\mathrm{N}$-acetyl glucosamine (Figure 1a) or $\mathrm{N}$-acetyl neuraminic acid (Figure 1b). The third gel image (Figure 1c) shows a typical gel run without affinity purification. Careful comparison of the gel images shows that $(i)$ in Figure 1, a or $b$, there is a change in glycosylated proteins found in plasma with time, and (ii) comparison of Figure 1, a with $\mathrm{b}$, shows that different glycoproteins are eluted using different sugars. This demonstrates that lectin affinity chromatography serves to bind glycosylated plasma proteins and not serum albumin, allowing the preparation of 2-D gel images that are not distorted by this protein. The results presented show the significant depletion of serum albumin with the yield of bound proteins ranging from $3.0 \%-6.2 \%$ of the total protein added to the beads (depending on the choice of eluting sugar) as determined by a Bradford protein assay (Pierce Biotechnology, Rockford, IL, USA).

The 2-D DIGE analysis revealed 547 features in Figure 1a, with $3.6 \%$ of the spots exhibiting greater than 3 -fold differences in abundance in sample 1 compared to sample 2. In Figure 1b, 737 spots were detected with a total of $1.6 \%$ differential expression. The mass spectrometric identification of proteins (from plasma/serum 2-D gels) in the $55-70 \mathrm{kDa}$ range is often confounded by the dominance and ubiquitous nature of serum albumin. We chose 100 spots from the $55-70$

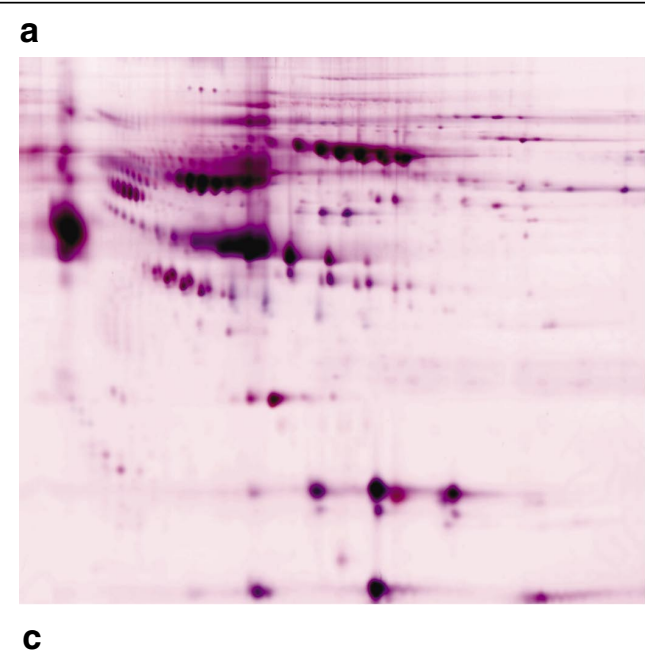

\section{b}

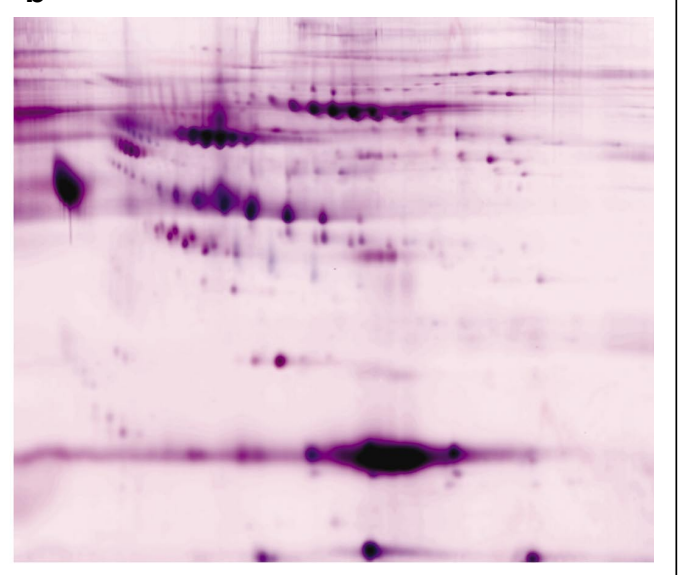

d

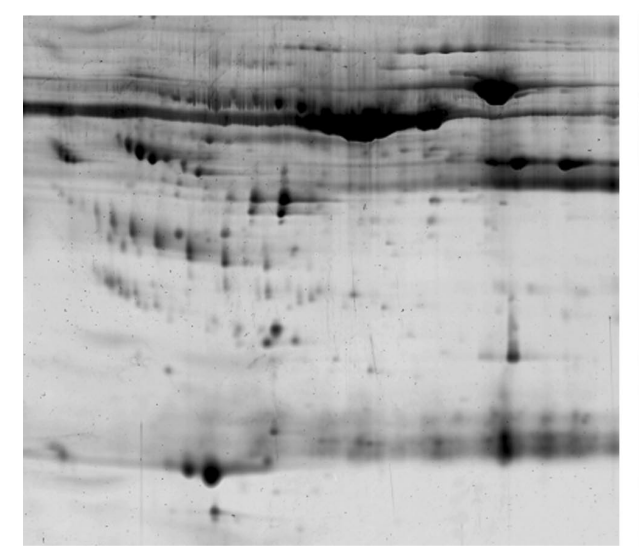

(n) $\mathrm{kDa}$ region and characterized them by MS to demonstrate the depletion of HSA. Seventeen of the proteins identified in this region are shown in Table 1. This shows that firstly, no spot was identified as serum albumin, and secondly, the depletion of HSA enabled the identification of a series of glycosylated hemopexins and several other proteins that would otherwise have been effectively masked by serum albumin. In addition, this method enabled the resolution of multiple occurrences of the same protein, with identical peptide mass fingerprints in the 45-70 kDa range, which differed between the two methods of sugar elution. This would indicate that these same protein spots are presumably due to differential glycosylation. Peptide mass fingerprinting or simple LC/MS/MS could not reveal many of these proteins in samples that were not HSA-depleted.

Two experiments iden-

\footnotetext{
Figure 1. Two-dimensional (2-D) difference gels of lectin-purified and unpurified plasma. Two blood samples were taken from the same individual at different times ( 0 and 1$)$ separated by 20 weeks. The samples from each time point were purified by binding to wheat germ agglutinin (WGA) immmobilized on agarose beads and eluted with either N-acetyl glucosamine or N-acetyl-neuraminic acid. Then samples were mixed and run on 2-D gels. (a) Proteins bound to WGA and eluted with $\mathrm{N}$-acetyl glucosamine are displayed as green (time 0 ; Cy3) or red spots (time 1; Cy5). (b) Proteins bound to WGA and eluted with $\mathrm{N}$-acetyl-neuraminic acid are displayed as green (time 0; Cy3) or red spots (time 1; Cy5). (c) Unfractionated plasma stained with SYPRO ${ }^{\circledR}$ Ruby. (d) The unbound fraction.
}

tical to that reported in Figure 1a were performed over a period of 3 weeks with the same sample but 
Table 2. Tryptic Peptide Sequences from Mass Spectrometric Data

\begin{tabular}{|c|c|c|c|c|c|c|c|c|}
\hline $\begin{array}{c}\text { Amino } \\
\text { Acid } \\
\text { Number }\end{array}$ & Observed & $\begin{array}{c}\mathrm{Mr} \\
\text { (expt) }\end{array}$ & $\begin{array}{c}\mathrm{Mr} \\
\text { (calc) }\end{array}$ & Delta & $\begin{array}{c}\text { Missed } \\
\text { Cleavages }\end{array}$ & Sequence & $\begin{array}{c}\text { Modification } \\
\text { Type }\end{array}$ & $\begin{array}{c}\text { Amino } \\
\text { Acid } \\
\text { Modified }\end{array}$ \\
\hline $145-152$ & 973.58 & 972.57 & 972.52 & 0.05 & 0 & EQLSLLDR & & \\
\hline $160-177$ & 1891.92 & 1890.91 & 1890.86 & 0.05 & 0 & LYGSEAFATDFQDSAAAK & & \\
\hline $198-214$ & 2096.05 & 2095.04 & 2095 & 0.04 & 0 & DLDSQTMMVLVNYIFFK & Oxidation & (M) \\
\hline $301-306$ & 766.3 & 765.29 & 765.37 & -0.07 & 0 & DSLEFR & & \\
\hline $307-315$ & 1061.59 & 1060.58 & 1060.58 & 0 & 0 & EIGELYLPK & & \\
\hline $321-340$ & 2296.24 & 2295.24 & 2295.16 & 0.07 & 0 & DYNLNDILLQLGIEEAFTSK & & \\
\hline $341-350$ & 960.55 & 959.54 & 959.5 & 0.04 & 0 & ADLSGITGAR & & \\
\hline $351-360$ & 1094.67 & 1093.66 & 1093.62 & 0.04 & 0 & NLAVSQVVHK & & \\
\hline
\end{tabular}

with different batches of WGA linked to agarose, and the experiments produced essentially identical patterns and identified $3.8 \%$ and $4.6 \%$ differences between the samples and treatments compared with $3.6 \%$ shown in Figure 1a. This shows that the experimental protocol is reproducible and is not dependent on the batch of WGA agarose. It should be remembered that the percentage reported by the software refers to the number of spots seen on a gel,

and this is not synonymous with the number of protein differences. Since the proteins purified by this procedure are glycosylated, and the same protein may vary in its glycosylation, a single protein, therefore, can give rise to a number of spots on a 2-D gel.

Proteins that were eluted in the nonbound fraction were electrophoresed on identical 2-D gels and showed the presence of a major spot in a position consistent with its identity as serum

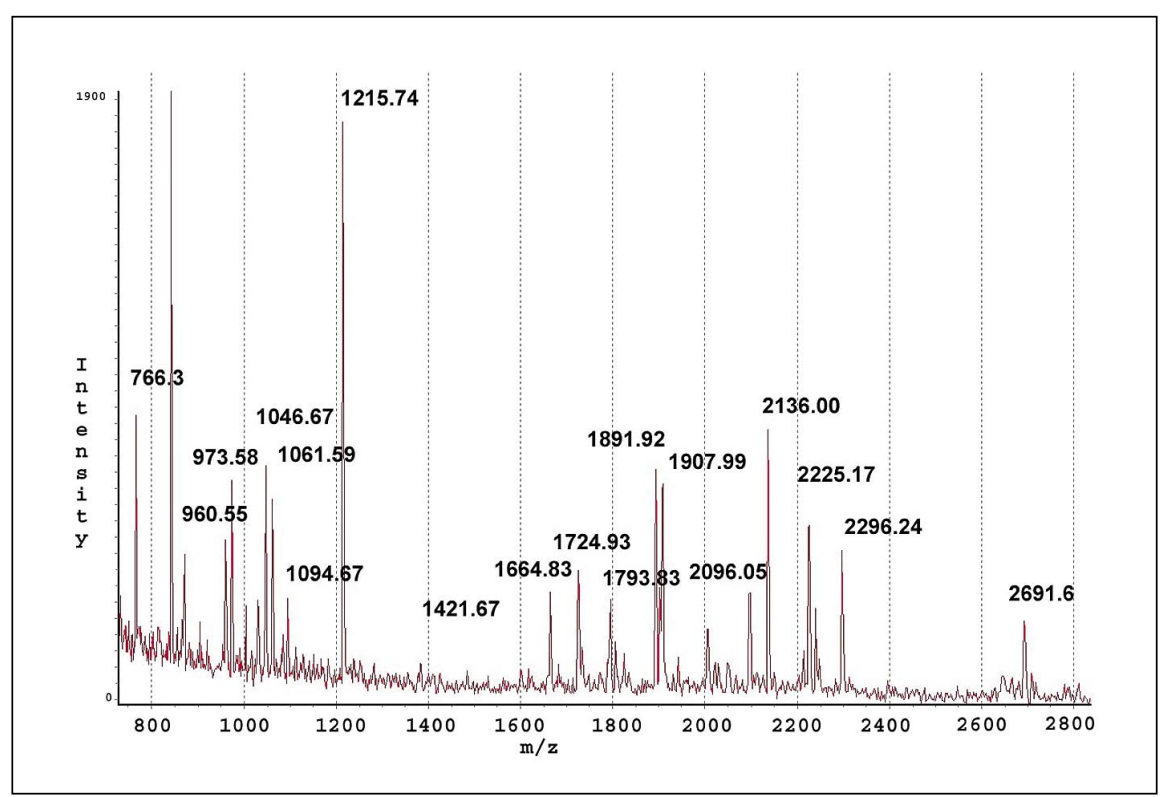

Figure 2. Mass spectrum of tryptic peptides derived from $\alpha$-1-antichymotrypsin. The mass spectrum was obtained using an Ettan MALDI-TOF/ PRO Mass Spectrometer. The peptide mass fingerprint is shown, and selected mass signal peaks are labeled with their mass to charge $(\mathrm{m} / \mathrm{z})$ values. albumin (Figure 1d). Faint spots were also seen corresponding to other proteins that eluted in the nonbound fraction. The pattern of spots appeared to be similar to the bound proteins (i.e., there did not appear to be selective enrichment for proteins other than serum albumin in the nonbound fraction).

This purification procedure does not affect the quality of the MS spectrum. The MS spectrum that allowed for the identification of $\alpha$-1-antichymotrypsin is shown in Figure 2 along with the corresponding peptide masses. The sequence of $\alpha$-1-antichymotrypsin is shown in Figure 3, and the sequences of all potential tryptic peptides have been annotated. They have been color-coded depending on whether they were identified (red) or not (green, blue, magenta, or black) in the MS spectrum. The assignment of these peptide masses to amino acid sequences in $\alpha$-1-antichymotrypsin is shown in Table 2. Of those that were not found in the MS spectrum, some were too small (green), too large (blue), or glycosylated (magenta) and so would not be detected in the experiment. Therefore, 18 of the 22 peptides with masses in the detectable size range were identified, and two of the four that were not found were potentially glycosylated and so would not have the predicted mass. This means that only two of the 22 potential peptides in the relevant mass range were not identified. The isolation of glycosylated proteins from plasma using lectin affinity results 


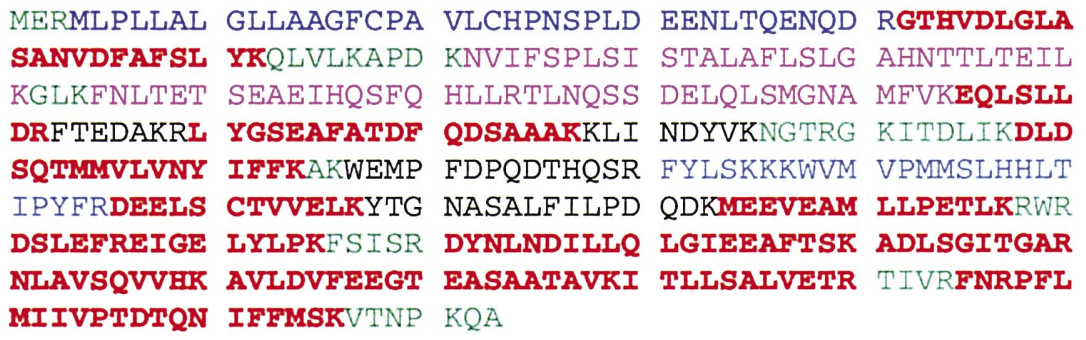

Identified Peptide

Peptide Mass Below Range of PMF Experiment

Peptide Mass Above Range of PMF Experiment

Likely Glycopeptide

Not found

Figure 3. Tryptic peptides found in $\alpha$-1-antichymotrypsin. The amino acid sequence of $\alpha-1$-antichymotrypsin is shown. The sequence is divided into discrete tryptic peptides, which are color-coded according to the legend at the bottom of the figure. The color coding signifies whether the peptide is found in the mass spectrum shown in Figure 2.

in near-total removal of serum albumin. This allows higher loading of sample and hence an increase in the less commonly represented plasma proteins, which in turn, leads not only to less distorted 2D gels but also to MS identification of a larger number of proteins not found when using total (nonlectin-bound) plasma proteins.

\section{REFERENCES}

1.Steel, L.F., M.G. Trotter, P.B. Nakajima, T.S. Mattu, G. Gonye, and T. Block. 2003. Efficient and specific removal of albumin from human serum samples. Mol. Cell Proteomics 2:262-270.

2.Tabar, L., P.B. Dean, C.S. Kaufman, S.W. Duffy, and H.H. Chen. 2000. A new era in the diagnosis of breast cancer. Surg. Oncol. Clin. N. Am. 9:233-277.

3.Zhou, G., H.M. Li, D. DeCamp, S. Chen, H.J. Shu, Y. Gong, M. Flaig, J.W. Gillespie, et al. 2002. 2D differential in-gel electrophoresis for the identification of esophageal scans cell cancer-specific protein markers. Mol. Cell Proteomics 1:117-124.

4.Wulfkuhle, J.D., D.C. Sgroi, H. Krutzsch, K. McLean, K. McGarvey, M. Knowlton, S. Chen, H.J. Shu, et al. 2002. Proteomics of human breast ductal carcinoma in situ. Cancer Res. 62:6740-6749.

5.Petricoin, E.F., A.M. Ardekani, B.A. Hitt, P.J. Levine, V.A. Fusaro, S.M. Steinberg, G.B. Mills, C. Simone, et al. 2002. Use of proteomic patterns in serum to identify ovarian cancer. Lancet 359:572-577.

6.Liotta, L. and E. Petricoin. 2000. Molecular profiling of human cancer. Nat. Rev. Genet. 1: 48-56.
7.Prasannan, L., D.E. Misek, R. Hinderer, J. Michon, J.D. Geiger, and S.M. Hanash. 2000. Identification of beta-tubulin isoforms as tumor antigens in neuroblastoma. Clin. Cancer Res. 6:3949-3956.

8.Emmert-Buck, M.R., J.W. Gillespie, C.P. Paweletz, D.K. Ornstein, V. Basrur, E. Appella, Q.H. Wang, J. Huang, et al. 2000. An approach to proteomic analysis of human tumors. Mol. Carcinog. 27:158-165.

9.Haney, P.J., C. Draveling, W. Durski, K. Romanowich, and M.W. Qoronfleh. 2003. SwellGel: a sample preparation affinity chromatography technology for high throughput proteomic applications. Protein Expr. Purif. 28:270-279.

10.Locke, V.L., T.S. Gibson, T.M. Thomas, G.L. Corthals, and D.B. Rylatt. 2002. Gradiflow as a prefractionation tool for twodimensional electrophoresis. Proteomics 2: 1254-1260

11.Christie, D.L. and D.J. Palmer. 1990. Identification and characterization of glycoproteins after extraction of bovine chromaffin-granule membranes with lithium di-iodosalicylate-purification of glycoprotein-ii from the soluble fraction. Biochem. J. 270:57-61.

Received 30 June 2003; accepted 22 September 2003.

Address correspondence to Henry Brzeski, Windber Research Institute, 600 Somerset Ave., Windber, PA 15963, USA. e-mail: h.brzeski@wriwindber.org 